\title{
8
}

\section{im

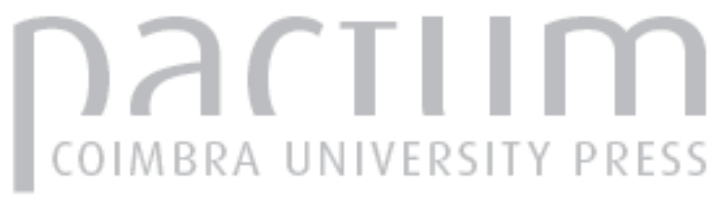

\section{[Recensão a] Alberto Prieto y Nicolás Marín, Religión e ideología en el Imperio Romano}

\author{
Autor(es): $\quad$ Dias, Maria Manuela Alves
}

Publicado por: Imprensa da Universidade de Coimbra

URL

persistente:

URI:http://hdl.handle.net/10316.2/45626

DOI:

DOI:https://dx.doi.org/10.14195/1647-8657_25_20

Accessed : $\quad$ 26-Apr-2023 15:55:20

A navegação consulta e descarregamento dos títulos inseridos nas Bibliotecas Digitais UC Digitalis, UC Pombalina e UC Impactum, pressupõem a aceitação plena e sem reservas dos Termos e Condições de Uso destas Bibliotecas Digitais, disponíveis em https://digitalis.uc.pt/pt-pt/termos.

Conforme exposto nos referidos Termos e Condições de Uso, o descarregamento de títulos de acesso restrito requer uma licença válida de autorização devendo o utilizador aceder ao(s) documento(s) a partir de um endereço de IP da instituição detentora da supramencionada licença.

Ao utilizador é apenas permitido o descarregamento para uso pessoal, pelo que o emprego do(s) título(s) descarregado(s) para outro fim, designadamente comercial, carece de autorização do respetivo autor ou editor da obra.

Na medida em que todas as obras da UC Digitalis se encontram protegidas pelo Código do Direito de Autor e Direitos Conexos e demais legislação aplicável, toda a cópia, parcial ou total, deste documento, nos casos em que é legalmente admitida, deverá conter ou fazer-se acompanhar por este aviso.

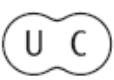


FACULDADE DE LETRAS

INSTITUTO DE ARQUEOLOGIA

CONIMBRIGA

$V O L U M E X X V$

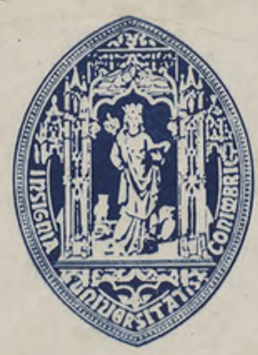

UNIVERSIDADE DE COIMBRA

1986 
ainda assinalar, pela sua extraordinária importância, a inscrição de Tijoia que testemunha a munificência de Voconia $Q$. $f$. Avita para com a sua Res Publica Tagilitana e que possibilitou a R. Lázaro fazer a identificação: Tagili — Tijoia (p. 91-92).

Maria Manuela Alves Dias

Alberto Prieto y Nicolás Marín, Religión e ideología en el Imperio Romano, ed. Akal, Madrid, 1979, $111 \mathrm{p}$.

«En estas páginas sólo presentamos una comprimida síntesis, ya que no hemos querido recárgala excesivamente de referencias no absolutamente necesarias, siendo nuestro único objectivo el exponer la teoría de que la religión actúa como AIE ( = «Aparato ideológico de Estado» = Aparelho ideológico do Estado) en la sociedad romana y que esta operación la realiza a través de la religión familiar, ciudadana e imperial. En la confección de este libro nuestras deudas básicas las colocamos en dos autores: Althusser y Staerman» (p. 9, Introducción). Estes são o propósito e os dois principais responsáveis teóricos indirectos deste pequeno livro que deverá ser entendido mais como urna proposta programática duma longa investigação em curso que como uma reflexão acabada e uma sugestão normativa sobre a função social da religião, como forma perfeita de ideologia activa, no Império Romano, ainda que, muitas vezes, os AA. escorreguem para a asserção de torn categórico.

O livro, propriamente dito, divide-se em três partes: I. Ideologia $y$ Realidad (p. 13-37); II. La Religión Griega (p. 39-58); III. La Religión Romana (p. 59-90); segue-se um Epílogo, sobre o Cristianismo e o fim do Mundo Antigo (p. 91-97), e as conclusões, gerais (p. 99-109). As duas primeiras partes, Ideologia e Realidade e A Religião Grega, servem, respectivamente, para a exposição dos pressupostos teóricos e para mostrar como «la religión es ya la base ideológica del mundo griego apoyada en dos pilares - familia y ciudad -, aunque habrá que esperar a Roma para que se manifiesten ya en pleno Imperio los tres pilares básicos de los AIE romanos: familia, ciudad e Imperio» (p. 7, Introdução). Na terceira parte, A Religião Romana, analisam-se as áreas sócio-ideológicas em que a religião tem papel preponderante na adaptação do inovador ao tradicional, permitindo uma superação das lacunas, que a religião antiga não preenchia, e que correspondem essencialmente a novas situações sociais de grupos carentes, e em busca de legitimação ideológico-religiosa; esta terceira parte subdivide-se em cinco capítulos que são outros tantos níveis de actuação religiosa. Os três primeiros, a família romana, a cidade romana e o culto imperial, dizem respeito a formas «previstas» na organização religiosa tradicional.

A análise da família romana, apoiada sobretudo nos estudos de Clara Gallini, Nino Turchi, Fustel de Coulanges, S. A. Tokarev e E. M. Staerman (p. 61-68), incide na sua qualidade de 'espaço religioso', ordenado pelo poder 
jurídico-ideológico do pater familiae, que se reproduzirá na categoria intermédia (a cidade) e, projectivamente, na categoria superior (o Império); a propósito da importância da família como «espaço religioso», os AA. recordam a asserção de Fustel de Coulanges de que para aquele que arriscava 'deixar a família equivalia a colocar-se fora de qualquer organização social e de qualquer direito, era perder os deuses e renunciar ao direito de rezar', situação cuja carga sócio-repressiva, evidente em demasia, não é explorada aliás; os cultos familiares (Manes, Lares, o dies natalis do pater familiae, Penates, Jano, Vesta, o génio individual do pater e Juno) servem também como aglutinador da família alargada, e dos seus meros dependentes, na bivalência repressiva e protectora: «Prueba de que el culto familiar era algo más que un mero formalismo y que actuaba como ideología lo tenemos en el hecho de que los mismos esclavos temerosos de un castigo corrían a refugiarse junto a los lares y penates», e, recordando S. A. Tokarev, escrevem os AA., "hay que anotar el hecho de que, posteriormente, los esclavos solían huir junto a las estatuas de los emperadores», e, ainda, «a los esclavos les estaba prohibido venerar otros dioses que los domésticos, es decir, el culto doméstico era el intento de mantener a los esclavos sometidos a la familia en el terreno de la ideología», e, seguindo E. M. Staerman, «en el pensamiento de Séneca se expresaba la idea de que la familia debía de ser para los esclavos como el Estado para los libres». O encadeamento do 'espaço religioso' familiar com o 'espaço religioso' da Cidade será feito através dos cultos dos Penates públicos, dos Lares protectores da Cidade, dos Lares viales, etc., e do desempenho de cargos religiosos municipais pelos próprios cidadãos e da adopção pública que garantia, para os casos de quebra sucessória, a continuidade da família como célula económica e sócio-ideológica. $\mathrm{O}$ encadeamento com o 'espaço religioso' da categoria superior, o Império, será feito através do culto ao imperador, institucionalizado no Culto Imperial; a acção político-religiosa de Augusto, restaurador de quase todos os cultos tradicionais romanos de âmbito municipal, é observada na sua preocupação de introduzir e difundir cultos aos Lares, aos Manes, aos Penates e ao génio do próprio Imperador e é na esteira de Robert Étienne que os AA. escrevem: «La familia imperial se presentaba, pues, como una familia más, con la diferencia de que el culto era público, en la ciudad, y a través de el todas las familias se vinculaban entre sí como miembros del Imperio Romano»; na mesma perspectiva se encontrarão os cultos de Apolo Palatino, da Venus Genitrix e de Mars Vitor (o deus vingador da morte de César); posteriormente, com os Severos, ou desde Adriano, teremos o culto da casa de Augusto, genericamente chamada casa do Imperador, a domus divina., que indirectamente colocava todos os cidadãos numa circunstância de clientela, seja de estreita fidelidade, em relação à família imperial. As ligações entre os três níveis categoriais, Família, Cidade, Império, são evidentes. Os cultos familiares mantinham unida a família romana, a gens. Cada cidade, como aglomerado orgânico de famílias, reproduzia no(s) culto(s) da cidade as formas praticadas nos cultos familiares. As especificidades próprias de cada cidade, no entanto, não impediam, do ponto de vista estrutural, que os seus cultos específicos 
se não representassem com força semelhante e mantivessem o seu significado próprio; a especificidade servia fundamentalmente ao reconhecimento da individualidade original como elemento aglutinador duma unidade social real. A nível superior, e precisamente porque os diversos cultos aparentavam um mesmo significado estrutural (havia já neles, à partida, nítidas características de unidade), foi possível, com o Principado, institucionalizar o Culto Imperial na base, organizado territorialmente nas cidades (a malha municipal). A implantação nos núcleos urbanos do Império do culto ao imperador e o facto de os sacerdotes do Culto Imperial serem eleitos para essas funções religiosas pelo mesmo sistema e eleitorado que intervinha na designação dos mais destacados dirigentes locais (e por, á semelhança dos cargos políticos, estes cargos religiosos implicarem, individualmente, uma certa capacidade económica para custear despesas sem qualquer contrapartida ou remuneração, acabando os eleitos por ser os representantes das camadas privilegiadas que, assim, iam juntar um cargo religioso de prestígio social aos cargos de direcção política que tinham desempenhado e podendo até muitos, depois do exercício do flaminato, ascender à carreira equestre) originaram, quer a nível itálico quer a nível provincial uma fortíssima 'rede de sustentação ideológica' político-religiosa do sistema. Foram, sem dúvida, os sacerdotes do Culto Imperial que garantiram a mais segura ligação ideológica entre o Estado romano e os habitantes das cidades, sobretudo as do ocidente do Império, e foi, também, através deles que nessas mesmas cidades se representaram (com autoridade) os interesses sociais, e económicos, do Estado. Numa análise social da evolução das religiões no Império, repara-se que os cultos orientais, e universalistas, e que a acção dos collegia funcionaram inicialmente com um 'complemento' supletivo social às insuficiências da capacidade de captação e influência religiosa e ideológica dos cultos mais antigos, progredindo em áreas populacionais que se foram tornando, pouco a pouco, cada vez mais importantes e influentes, e que os cultos familiares e citadinos não conseguiriam acompanhar, adaptando-se convenientemente, sem correrem o risco de pôr em causa a estrutura orgânica da sua própria base social; tendo os núcleos urbanos (e, entre estes, os de maior desenvolvimento económico) como áreas de implantação, os collegia organizaram as suas formas culturais formalmente à imagem das dos cultos familiares tradicionais, no intuito de unir, entre si, indivíduos que mantinham laços que não eram naturalmente de estrutura gentílica, mas que tendiam a constituir (por assunção superior das formas de associação e corporação) um novo tipo de 'família'. Como formas não 'previstas' na organização religiosa tradicional, os collegia, autênticas associações religiosas 'paralelas', tenderiam, nalguns casos, posteriormente, para indirectamente assumirem características convergentes com as dos cultos familiares, de cidade e estatais; a sua contaminação pelos agentes do Culto Imperial parece ter sido feita pelos collegia dos sêxviros augustais que, assim, canalizaram para o culto imperial um grupo sócio-económico em ascensão que, uma vez nele integrado, se tornou cúmplice e agente dos propósitos da política ideológica do Império. Também, face aos cultos orientais que fugiam ao âmbito da família e da cidade e que tinham 
como mais fervorosos cultuantes os estrangeiros (entendidos aqui como elementos exógenos às comunidades e não como estranhos à geografia do Império), o Culto Imperial irá, através de acções de sincretismo religioso, procurar associá-lo ao próprio culto do imperador; assim, no culto, com as invocatorias às clássicas divindades augustaicas vão também aparecer outras, como a de Isis Augusta ou a Nemesis Augusta, exemplificando uma clara tentativa de captação dos cultos estrangeiros pelo Culto Imperial. Ora, apesar de toda a sua versatilidade, o Culto Imperial não foi capaz de assimilar e integrar quer religiões de carácter universalista e de salvação, como o Cristianismo, quer religiões, como o Judaísmo, onde a componente do messianismo nacionalista era preponderante ou muito, muito forte. A progressiva orientalização 'epidérmica' dos cultos oficiais, como a teologia solar de Heliogabalo, ou a de Aureliano, de cariz demasiado formal, simbólico e, simultaneamente também, demasiado especulativo, 'abstracto', a necessidade social duma alternativa ontológica e ética, prática e compensada, que o estoicismo de segunda mão (senão de conveniência literária e palaciana), de presença fugaz sob os Antoninos, não tinha sabido comunicar e as contradições do Culto Imperial (aliás um AIE por excelência) favoreceram o rápido apogeu dos cultos mistéricos orientais de salvação. Dirigidos fundamentalmente ao indivíduo, em si, e reservados, nas práticas cultuais, aos iniciados, os cultos de salvação tinham invariavelmente uma proposta que, socialmente, transbordando o âmbito da família, da cidade e do Império, colocava cada qual, individualmente, perante uma resposta cósmico-religiosa necessariamente desejada e suficientemente compensad(or)a. Estavam neste caso religiões de salvação como o Mitraísmo e o Cristianismo.

O Cristianismo, aberto a todos e a cada um, para as suas fileiras, não exigia o ser-se cidadão, nem o estar-se ligado a uma gens, ou, sequer, ser-se habitante de dentro das fronteiras do Império. Assim, ao transcender os quadros político, organizativo e territorial do Império Romano, o Cristianismo fugia ao controlo político e ideológico da religião, controlo que deixava, portanto, de estar nas mãos do Imperador, esse antigo paxer familias no Poder, pater Patriae e cúpula do sistema sócio-económico gentílico. De Roma (a Urbs, cidade terrena) vai surgir uma nova cidade, a cidade divina, indiciando uma outra fase da História da Humanidade (cf. p. 109).

A característica (e vantagem) principal deste pequeno livro é poder-se ler nele muito mais do que nele está escrito.

Maria Manuela Alves Dias 